Actions required

1. Clear guidance at induction on how to escalate concerns both within the employer and the local office.

2. That naming or investigating a concern under a 'Dignity at Work Policy' does not immediately reassure the individual that their complaint of bullying, undermining or discrimination will be recognised as such.

3. Ensure timely investigation and communications.

4. Differences between Revalidation and ARCP processes made clear to doctors in training.

5. Visa sponsorship rules on salary thresholds may preclude some doctors training LTFT.

Importantly, examples of good practice and positive experiences were highlighted. Overall, attendees were supportive of each other, exchanging challenges faced and how they have overcome them, creating interpersonal camaraderie. We anticipate continuing to work together to make beneficial change through future Assemblies.

\section{NATIONAL VITAMIN A PLUS CAMPAIGN (NVAC), 2020 DURING COVID-19 PANDEMIC SITUATION: EXPERIENCE FROM BANGLADESH}

Tasnim Rahman Disu*, Vitamin A Plus Cell, IPHN. Institution of Public Health Nutrition, Dhaka, Bangladesh

\subsection{6/leader-2021-FMLM.45}

Aims National Vitamin A Plus Campaign (NVAC), 2020 which is a Government Program of Bangladesh was implemented to reduce Childhood blindness, Vitamin A deficiency and boosting immunity along with enhanced leadership skills during COVID-19 pandemic situation.

Methods A Mixed method study was implemented aiming to provide intervention with blue colored vitamin A capsules to children aged between 6 to 11 months and red capsules to children aged between 12 to 59 months covering 120,00 distribution centers (permanent) in entire Bangladesh for two weeks (4-17) October, 2020. Supplementation was given by trained health workers and volunteers. RTMR (Real-Time Monitoring \& Reporting) was used for the NVAC, 2020 to report using cellular devices during campaign operations which was observational in nature. Around 14,000 data were collected. SPSS Version 22.0 was used for analysis.

Results Despite the challenges presented by COVID-19, NVAC, 2020 reached 97 per cent of the target population. During NVAC 2020, 2.53 million children aged between 6 to 11 months and 19.5 million children aged between 12 to 59 months has been provided covering 120,00 distribution centers in Bangladesh. Around 1450 monitors from central level visited almost 14,000 distribution centers while the NVAC was ongoing. Protective measures during COVID-19 were taken appropriately by the volunteers and health workers. The study showed a successful situational leadership and management in healthcare system as well as awareness of community level people though there was a fear of unknown due to COVID19.

Conclusions Vitamin A capsule supplementation is not only for blindness prevention but also for boosting overall immunity in children. So the approach of NVAC 2020 may guide us towards more successful health interventional programs leading to a better future with more empowered skilled leadership.
NVAC; Childhood Blindness; Leadership; COVID-19 pandemic situation;

\section{NAVIGATING THE STORM: STRUCTURING AND SUPPORTING JUNIOR DOCTOR WELLBEING DURING THE COVID-19 PANDEMIC}

Avneet Shahi, Alyssia Broomfield. Hampshire Hospitals Foundation Trust, UK

\subsection{6/leader-2021-FMLM.46}

The COVID-19 pandemic has had profound consequences for junior doctors. At a foundation trust with 2 district general hospital sites, we initiated a multi-faceted programme of support for 390 junior doctors. This was led by the Chief Residents (CR) utilising senior management, clinical psychologists, mess committees and communications team. The programme was inclusive, with a focus on the Foundation Year 1 (FY1) cohort. Junior doctors are often the least experienced of the medical team; the second wave presented a unique challenge for FY1s- who had only ever practised within a pandemic. Weekly CR meetings were held and feedback sought pre- and post- intervention. Initiatives targeted four areas: information, support, social and achievement recognition. Interventions included: evening Junior Doctor COVID-19 updates; prioritisation of the annual Junior Doctor Awards (JDAs); onceweekly bitesize, non-urgent updates instead of anxiety-provoking multiple daily emails; FY1s' support cafés, online mess events and enhanced support through evening sessions with clinical psychologists. COVID-19 evening updates were popular, with a peak of 84 attendees. Feedback was encouraging, indicating a demand for these to continue post-pandemic. The clinical psychologists were well-received with informal feedback praising the sessions. FY1s' support cafés, unfortunately, were hampered by poor turnout during the day. The JDAs received a record number of nominations locally (over 200), and feedback indicated that doctors felt, for the first time in many months, valued and appreciated. Priorities now, are physician burnout and junior doctor attrition: innovative approaches are needed. To provide sensitive support, timing of opportunities must be carefully considered; junior doctors can rarely be released from clinical duties to attend events during working hours. Wellbeing support must be delivered alongside sufficient practical assistance otherwise interventions risk insincerity.

\section{NURSE LEADERSHIP DURING PANDEMIC IN TERTIARY CARE HOSPITALS OF GULBARGA CITY, INDIA.}

Nilofer Naaz*, Shantkumar Nigudgi, Pallavi V T, Shreeshail G, Della. Department of Community Medicine, M.R Medical College, Gulbarga, INDIA

\subsection{6/leader-2021-FMLM.47}

Background This study across two leading hospitals of the City will help in understanding the functioning of nursing care and its importance during crisis like Covid-19 pandemic. It will help us to ascertain the level of preparedness of the healthcare facilities to tackle any future emergencies as well. As Gulbarga was one of the first few cities in the Karnataka state of India during the second wave of Covid-19 to cope sooner and better in comparison to others, a post Covid 